\title{
Phenolic content, anti-inflammatory and antioxidant activities of Anacyclus clavatus extracts
}

\author{
Hamama Bouriche ${ }^{1 *}$, Abdallah Kherbache ${ }^{1}$, Seoussen Kada ${ }^{1}$, Abderrahmane Senator ${ }^{1}$, \\ Ibrahim Demirtas ${ }^{2}$
}

${ }^{1}$ Laboratory of Applied Biochemistry, Faculty of SNV, Department of Biochemistry, University Ferhat Abbas Setif 1, Algeria

${ }^{2}$ Department of Chemistry, Faculty of Science, Çankırı Karatekin University, Çankırı, Turkey

*Corresponding author, E-mail: bouriche_ha@yahoo.fr

\begin{abstract}
The anti-inflammatory and the antioxidant activities of methanol (ME) and aqueous (AE) extracts of Anacyclus clavatus were evaluated. Phenolic constituents in the extracts were screened. Croton oil-induced ear edema in mice, carrageenan-induced paw edema and pleurisy in rats were evoked. The antioxidant effect was tested by 1,1-diphenyl-2-picrylhydrazyl, ion chelating, lipid peroxidation tests. Both extracts are rich in phenolic compounds. The application of $2 \mathrm{mg}$ per ear of ME or AE inhibited ear edema by 84 and $83 \%$, respectively. The oral treatment of rats with 200 or $400 \mathrm{mg} \mathrm{kg}^{-1}$ of ME reduced paw edema by 64 and $74 \%$, respectively, whereas the inhibition by AE was by 65 and $80 \%$, respectively. At $400 \mathrm{mg} \mathrm{kg}^{-1}$, the extracts decreased exudation and neutrophil migration into the pleural cavity by 64 and $66 \%$, respectively, while the inhibition by AE was 42 and 55\%, respectively. On the other hand, ME exerted scavenging activity higher than AE, while the AE chelating activity was more than that of ME. However, both extracts had similar inhibitory effect on lipid peroxidation. In general, A. clavatus may be used as a source of anti-inflammatory and anti-oxidant agents.
\end{abstract}

Key words: Anacyclus clavatus, anti-inflammatory activity, antioxidant activity, phenolic compounds.

Abbreviations: AE, aqueous extract; BHT, butylated hydroxytoluene; DPPH, 1,1-diphenyl-2-picrylhydrazyl; ME, methanol extract.

\section{Introduction}

An imbalance between oxidants and antioxidants leads to oxidative damage to biological molecules, including lipids, proteins and nucleic acids. This damage is responsible for the pathogenesis of several human diseases, such as neurodegenerative diseases, lung diseases, cardiovascular diseases, diabetes, and atherosclerosis (Rahman et al. 2012). Moreover, when overproduced, reactive oxygen species attack tissue and then provoke an inflammatory response by production of pro-inflammatory mediators and chemotactic factors, which amplify the inflammation, resulting in chronic inflammation (Mittal et al. 2014). In fact, chronic inflammation is another important factor that may cause or contribute in the pathogenesis of many diseases. Thus, scavenging reactive oxygen species and suppressing their formation, either by inhibiting enzymes or by chelating trace elements involved in free radical production, are thought to be an effective means to depress the level of oxidative stress of organisms.

Usually, phytochemicals possess strong antioxidant ability as well as anti-inflammatory action, which are also the basis of other bioactivities and health benefits. Antioxidants can reduce inflammation via the inhibition of pro-inflammatory mediators, as well as the increase of the anti-inflammatory mediator production (Costa et al. 2013; Moura et al. 2015).

Medicinal plants may offer an alternative source for the anti-inflammatory and antioxidant drugs, and have significant effect against several pathologies. Various bioactive compounds from plants were discovered as a new medicinal drug (Lahlou 2013).

Anacyclus clavatus Pers. is an aromatic medicinal plant belonging to the Asteraceae family. It is widely distributed in the Mediterranean countries and known for its medicinal properties. In Algerian traditional medicine, the aerial parts of this plant are used to dispel gas and prevent bloating. Its leaves and stems are used as digestive herbal tea and as a traditional remedy against digestive disorders (Benitez, Gonzalez-Tejero 2010).

Phytochemical analysis revealed the presence of essential oils in the leaves/stems and flower extracts of $A$. clavatus (Aliboudhar, Tigrine-Kordjani 2013). Some of these compounds exhibit antibacterial activity (Hammami et al. 2013), and antitumour activity (Yi-Qun et al. 2008). Few studies have been reported that have shown the antiinflammatory activity of $A$. clavatus. The current study was designed to evaluate anti-inflammatory activity and antioxidative capacity of different extracts of A. clavatus by using a series of in vivo and in vitro tests. 


\section{Materials and methods}

\section{Chemicals}

Indomethacin, ferrosine [3-(2-pyridyl)-5, 6-bis(4phenyl-sulfonicacid)-1,2,4-triazine)], $\mathrm{FeCl}_{2}, \mathrm{FeCl}_{3}$, EDTA, trichloroacetic acid, potassium thiocyanate, 1,1-diphenyl2-picryl-hydrazyl (DPPH), folin-ciocalteu, gallic acid, tannic acid, quercetin, $\left.\mathrm{K}_{3} \mathrm{Fe}(\mathrm{CN})_{6}\right], \mathrm{Na}_{2} \mathrm{CO}_{3}$, Tween 20, $\lambda$-carrageenin, carboxymethyl cellulose, aspirin and croton oil were purchased from Sigma (Germany). Linoleic acid and 2,6-di-tert-butyl-4-methylphenol (butylated hydroxytoluene; BHT) was obtained from Fluka (France). All other reagents were of analytical grade and supplied from Panreac (Spain), Riedel-de Haen, Prolabo and Sigma (Germany).

\section{Plant material}

The plant Anacyclus clavatus was collected in May 2012 from Bougaa area in Algeria. The plant was identified and authenticated taxonomically. A voucher specimen (No. A.C. 2012-1) was preserved for future reference at the local Herbarium of Botany, Department of Botany, University of Sétif 1 . The aerial part was air-dried at room temperature, then reduced to powder and stored away from light until use.

\section{Animals}

Swiss albino mice weighing 25 to $30 \mathrm{~g}$ and Albino Wistar rats weighing 170 to $210 \mathrm{~g}$ of either sex were obtained from the Pasteur Institute of Algiers, Algeria. All animals were kept to acclimatize under the laboratory conditions for one week and were provided with standard rodent diet and water ad libitum. Animals were randomly selected for different experimental groups (six animals per group) and fasted overnight prior to the experiments. All procedures were performed in accordance with European Union Guidlines for Animal Experimentation (2007/526 /EC).

\section{Preparation of Anacyclus clavatus extracts}

Methanol extract (ME) of $A$. clavatus was obtained by

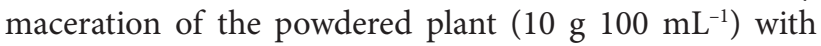
$80 \%$ methanol for $24 \mathrm{~h}$ under continuous shaking at room temperature. After filtration, the filtrate was concentrated under reduced pressure at $40^{\circ} \mathrm{C}$. The residue was lyophilized to give a dark brown powder (yield 19\%).

Aqueous extract (AE) of A. clavatus was prepared by boiling $50 \mathrm{~g}$ of powdered plant in $500 \mathrm{~mL}$ distilled water for $20 \mathrm{~min}$, followed by filtration and centrifugation for 10 min. The supernatant obtained was lyophilized to give a dark brown powder (yield 17\%). Both extracts were stored at $-32^{\circ} \mathrm{C}$ until use.

\section{Determination of total polyphenol concentration}

The concentration of total phenolics in the extracts was determined according to a modified method of
Li et al. (2007). Briefly, a volume of $100 \mathrm{~mL}$ of various concentrations of extracts solutions was added to $500 \mathrm{~mL}$ of Folin-Ciolcalteu (10\%). After $4 \mathrm{~min}, 400 \mathrm{~mL}$ of 7.5\% $\mathrm{Na}_{2} \mathrm{CO}_{3}$ was added. The mixture was shaken for $2 \mathrm{~h}$ at room temperature and the absorbance was recorded at $765 \mathrm{~nm}$. Gallic acid was used as a standard. The concentration of total phenolic compounds in the extracts was determined as $\mathrm{mg}$ of gallic acid equivalent per $1 \mathrm{~g}$ of extract (mg GAE $\mathrm{g}^{-1}$ extract).

\section{Determination of flavonoid concentration}

Total flavonoid concentration in the extracts was determined according to Bahorun et al. (1996). Briefly, $1 \mathrm{~mL}$ of $2 \% \mathrm{AlCl}_{3}$ in ethanol was added to $1 \mathrm{~mL}$ of the extracts $(2$ $\mathrm{mg} \mathrm{mL}{ }^{-1}$ ). After $10 \mathrm{~min}$ of incubation at room temperature, the absorbance was measured at $430 \mathrm{~nm}$. Quercetin was used as a standard. Total flavonoid content was expressed as $\mathrm{mg}$ of quercetin equivalent per $1 \mathrm{~g}$ of extract $\left(\mathrm{mg} \mathrm{QE} \mathrm{g}^{-1}\right.$ extract).

\section{Determination of tannin concentration}

Tannin concentration was determined using the hemoglobin precipitation assay according to Hagerman, Butler (1989). Tannic acid was used as standard. An aliquot of $0.5 \mathrm{~mL}$ of each extract was mixed with $0.5 \mathrm{~mL}$ of hemolyzed bovine blood. The mixture was reacted for $20 \mathrm{~min}$ at room temperature, and then subjected to centrifugation at 4000 $\mathrm{rpm}$ for $10 \mathrm{~min}$ at $4{ }^{\circ} \mathrm{C}$. The absorbance was measured at $576 \mathrm{~nm}$ and tannic content was expressed as $\mathrm{mg}$ tannic acid equivalent per $\mathrm{g}$ of extract (TAE $\mathrm{g}^{-1}$ extract).

\section{HPLC-TOF/MS analysis}

HPLC-TOF/MS analysis of A. clavatus extracts was carried out as described elsewhere (Abay et al. 2015). This HPLC method was developed and validated to analyze phenolic acids and flavonoids in the plant extracts. An Agilent Technology of 1260 Infinity HPLC System was coupled with a 6210 Time of Flight (TOF) LC/MS detector and ZORBAX SB-C18 $(4.6 \times 100 \mathrm{~mm}, 3.5 \mu \mathrm{m})$ column. Mobile phases $A$ and $B$ were ultra-pure water with $0.1 \%$ formic acid and acetonitrile, respectively. Flow rate was $0.6 \mathrm{~mL} \mathrm{~min}^{-1}$ and column temperature was $35^{\circ} \mathrm{C}$. Injection volume was $10 \mu \mathrm{L}$. The solvent program was as follow: 0 to $1 \mathrm{~min} 10 \% \mathrm{~B}$; 1 to $20 \mathrm{~min} 50 \% \mathrm{~B} ; 20$ to $23 \mathrm{~min} 80 \% \mathrm{~B} ; 23$ to $25 \mathrm{~min} 10 \%$ $\mathrm{B} ; 25$ to $30 \mathrm{~min} 10 \% \mathrm{~B}$. Ionization mode of the HPLC-TOF/ MS instrument was negative and operated with a nitrogen gas temperature of $325^{\circ} \mathrm{C}$, nitrogen gas flow of $10.0 \mathrm{~L} \mathrm{~min}^{-1}$, nebulizer of $40 \mathrm{psi}$, capillary voltage of $4000 \mathrm{~V}$ and finally, fragmentor voltage of $175 \mathrm{~V}$. For sample analysis, dried crude extracts $(200 \mathrm{ppm})$ were dissolved in methanol at room temperature. Samples were filtered passing through a $\operatorname{PTFE}(0.45 \mu \mathrm{m})$ filter by an injector to remove particulates.

\section{Croton oil induced ear edema in mice}

Croton-oil induced ear edema was evoked according to 
Manga et al. (2004). Cutaneous inflammation was induced in the inner surface of the right ear of mice (6 mice per group) by application of $15 \mu \mathrm{L}$ acetone containing $80 \mu \mathrm{g}$ croton oil as an irritant. Treated animals received topically $2 \mathrm{mg}$ per ear of methanol, aqueous extract of A. clavatus (disolved in acetone/water) or $0.5 \mathrm{mg}$ per ear of indomethacin, used as reference drug. The thickness of ears was measured before and $6 \mathrm{~h}$ after the induction of inflammation using a dial calliper. The edema was expressed as an increase in the ear thickness due to croton oil application.

\section{Carrageenan induced paw edema in rats}

Paw edema was induced by injecting $0.1 \mathrm{~mL}$ of $1 \%$ $\lambda$-carrageenan into the subplantar region of the right hind paw of rats (Winter et al., 1962). One hour before carrageenan injection, rats received orally 200 and $400 \mathrm{mg}$ $\mathrm{kg}^{-1}$ of A. clavatus methanol, aqueous extract (prepared in saline solution) or $200 \mathrm{mg} \mathrm{kg}^{-1}$ aspirin (suspended in CMC 1\%). Rats of control group were injected with $0.1 \mathrm{~mL}$ $\lambda$-carrageenan and received orally only the vehicle before the injection. To assess the edema the injected paw was measured using a plethysmometer (UGO Basile, Varese, Italy) initially $\left(V_{0}\right)$ and $1,2,3,4,5$, and $6 \mathrm{~h}$ after carrageenan injection $\left(V_{t}\right)$. Inflammation was calculated as the increase in volume of the paw after treatment subtracted from the basal volume. Results were expressed as percentage of inhibition of edema, calculated according to the following equation:

$$
\begin{aligned}
\% \text { inhibition }= & {\left[\left(V_{t}-V_{0}\right) \text { control }-\left(V_{t}-V_{0}\right) \text { treated }\right] / } \\
& \left.\left(V_{t}-V_{0}\right) \text { control }\right] \times 100 .
\end{aligned}
$$

\section{Carrageenan-induced pleurisy in rat}

The carrageenan-induced pleurisy in rats was assessed according to Cuzzocrea et al. (1998). Treated rats (six rats per group) were administered orally $2 \mathrm{~mL}\left(400 \mathrm{mg} \mathrm{kg}^{-1}\right)$ of methanol or aqueous extract of A. clavatus (prepared in saline solution), one hour before the intra-pleural injection of $0.2 \mathrm{~mL}$ of the $\lambda$-carrageenan $1 \%$. Rats of the untreated control group were treated orally with $2 \mathrm{~mL}$ of saline solution. Animals were lightly anaesthetized with chloroform and submitted to a skin incision at the level of the left sixth inter-costal space. The underlying muscle was dissected and saline solution $(0.2 \mathrm{~mL})$ containing $1 \% \lambda$ -carrageenan $(0.2 \mathrm{~mL})$ was injected into the pleural cavity. For rats of the negative control group, $0.2 \mathrm{~mL}$ of sterile $0.9 \% \mathrm{NaCl}$ instead of the $\lambda$-carrageenan solution was injected in their pleural cavity and they were not treated with any other substance. The skin incision was closed with a suture and the animals were allowed to recover. Four hours after the injection of $\lambda$-carrageenan, rats were killed and their chests were carefully opened, and the pleural cavity is subsequently washed with $2 \mathrm{~mL}$ of heparinized saline solution. The exudate and washing solution were removed by aspiration and the total volume was measured. Any exudate, contaminated with blood was discarded. The amount of exudates was calculated by subtracting the volume injected $(2 \mathrm{~mL})$ from the total volume recovered. The leukocytes in the exudate were suspended in PBS and counted with an optical microscope after vital Trypan blue staining.

\section{DPPH radical scavenging assay}

The free radical scavenging activity of $A$. clavatus methanol and aqueous extracts was measured using 1,1-diphenyl-2picryl-hydrazil (DPPH), according to the method described by Que et al. (2006) with slight modifications. A volume of $500 \mathrm{~mL}$ of the DPPH solution $(0.1 \mathrm{mM})$ was added to $500 \mathrm{~mL}$ of extract solutions or standard (BHT) at different concentrations, the mixture was incubated in the dark for $30 \mathrm{~min}$ at room temperature, and then the absorbance was recorded at $517 \mathrm{~nm}$. The percentage of DPPH scavenging activity was calculated by the following equation:

Scavenging activity $(\%)=\left[\left(A_{c}-A_{t}\right) / A_{c}\right] \times 100$, where $A_{c}$ is the absorbance of the control (in the absence of the abstracts) and $A_{t}$ is the absorbance of the test sample (in the presence of the extracts).

\section{Metal chelating activity}

The chelating of ferrous ions by methanol and aqueous extracts of A. clavatus was estimated by the method of Li et al. (2007). Briefly, extract samples at different concentrations were added to a solution of $0.6 \mathrm{mmol} \mathrm{L}^{-1} \mathrm{FeCl}_{2}(50 \mu \mathrm{L})$. The reaction was initiated by the addition of $50 \mu \mathrm{l}$ of ferrozine $(5 \mathrm{mM})$ and the mixture was shaken vigorously and left standing at room temperature for $10 \mathrm{~min}$. Absorbance of the solution was then measured spectrophotometrically at 562 $\mathrm{nm}$. The percentage of inhibition of ferrozine- $\mathrm{Fe}^{2+}$ complex formation was calculated. EDTA was used as a reference. The percentage of chelating activity was calculated using the following equation:

Chelating activity $(\%)=\left[\left(A_{c}-A_{t}\right) / A_{c}\right] \times 100$, where $A_{c}$ is the absorbance of control (in the absence of the abstracts) and $A_{t}$ is the absorbance of the test sample.

\section{Total antioxidant activity}

The total antioxidant activity of methanolic and aqueous extracts of A. clavatus was determined according to the thiocyanate method using a linoleic acid system (Gulcin et al. 2005) with slight modifications. The linoleic acid emulsion was prepared by mixing $0.028 \mathrm{~g}$ linoleic acid, $0.028 \mathrm{~g}$ Tween 20 and $10 \mathrm{~mL}$ phosphate buffer $(0.04 \mathrm{M}$, $\mathrm{pH}$ 7.0). The mixture was then homogenized, and 0.6 $\mathrm{mL}$ phosphate buffer containing $0.6 \mu \mathrm{L}$ plant extract and BHT $\left(50 \mu \mathrm{g} \mathrm{mL}^{-1}\right)$ were mixed with $0.6 \mathrm{ml}$ of linoleic acid emulsion. The mixed solutions were incubated at $25^{\circ} \mathrm{C}$ in the dark for $96 \mathrm{~h}$. The peroxide level was determined after reaction of $20 \mu \mathrm{L}$ of sample solution with $20 \mu \mathrm{L}$ of $\mathrm{FeCl}_{2}$ $(20 \mathrm{mM}$ in $3.5 \% \mathrm{HCl})$ and $20 \mu \mathrm{L}$ thiocyanate $(30 \%)$. The absorbance of each mixture was determined at $500 \mathrm{~nm}$ after 3 min of reaction and every $24 \mathrm{~h}$ for $96 \mathrm{~h}$. During linoleic acid oxidation, the peroxides formed oxidize $\mathrm{Fe}^{2+}$ to $\mathrm{Fe}^{3+}$. The $\mathrm{Fe}^{3+}$ form a complex with $\mathrm{SCN}^{-}$and this complex 
Table 1. Polyhenols, tannins and flavonoids content of $A$. clavatus methanol extract (ME) and aqueous extract (AE). Values are mean \pm $\mathrm{SD}(n=3)$. GAE, gallic acid equivalents; QE, quercetin equivalents; TAE, tannic acid equivalents

\begin{tabular}{|c|c|c|c|}
\hline Extract & Polyphenols (mg GAE $\mathrm{g}^{-1}$ extract) & Flavonoids (mg QE $\mathrm{g}^{-1}$ extract) & Tannins (mg TAE $\mathrm{g}^{-1}$ extract) \\
\hline $\mathrm{ME}$ & $131.30 \pm 6.88$ & $9.96 \pm 0.43$ & $39.21 \pm 6.55$ \\
\hline $\mathrm{AE}$ & $79.06 \pm 3.24$ & $16.39 \pm 1.38$ & $31.14 \pm 2.27$ \\
\hline
\end{tabular}

has a maximum absorbance at $500 \mathrm{~nm}$. Therefore, high absorbance indicated high linoleic acid oxidation. The percent inhibition of lipid peroxidation was calculated according to the following equation:

Peroxidation inhibition $(\%)=\left[\left(A_{c}-A_{t}\right) / A_{c}\right] \times 100$, where $A_{c}$ is the absorbance of control (in the absence of the abstracts) and $A_{t}$ is the absorbance of the test sample.

\section{Statistical analysis}

Results were expressed as mean $\pm \mathrm{SD}$ in vitro and as mean $\pm \mathrm{SE}$ in vivo. The significance of differences between control and the various tests was determined by an ANOVA test followed by a Dunnett/Tukey test for multiple comparisons. The differences were considered statistically significant at $p$ $\leq 0.05$.

\section{Results}

\section{Polyphenol, flavonoid and tannin content}

Table 1 shows that methanol extract of A. clavatus was richer in polyphenols and tannins than the aqueous extract, while the aqueous extract was richer in flavonoids than methanol extract.

\section{HPLC-TOF/MS analysis}

HPLC-TOF/MS analysis revealed the presence of phenolic acids and flavonoids in the A. clavatus extracts (Table 2 and Fig. 1). However, methanol extract was richer than the aqueous one. Chlorogenic acid was detected as major constituent (1839.77 mg kg-1 of plant) of $\mathrm{ME}$, while apigetrin was detected as a major flavonoid (505.74 $\mathrm{mg} \mathrm{kg}^{-1}$ of plant) in this extract. Moreover this extract contained high amounts of apegenin, diosmin and quercetin-3$\beta$-D-glucoside. Several compounds (caffeic acid, rutin, quercetin-3- $\beta$-D-glucoside, sinapic acid, polydatine and apigenin) were detected as traces in AE.

\section{Effect of Anacyclus clavatus extracts on croton oil-induced ear edema in mice}

The mice in the control group that received only the croton oil solution developed after 6 hours an edema characterized by an increased thickness $(94 \pm 9.7 \mu \mathrm{m})$. The treatment with $2 \mathrm{mg}$ per ear of the methanolic extract induced a very significant reduction $(p<0.001)$ of inflammation compared to the control mice group. The increase in thickness after 6 hours was $20 \pm 8.3 \mu \mathrm{M}$, which corresponded to an inhibition of $84 \%$. The aqueous extract exerted almost the same effect as the methanol extract (83\%) (Fig. 2). This inhibition was better than that exerted by $0.5 \mathrm{mg}$ per ear of indomethacin $(70 \%)$, used as a reference anti-inflammatory agent.

\section{Effect of Anacyclus clavatus extracts on carrageenan- induced paw edema}

The subplantar injection of carrageenan in the control group caused edema with a maximum volume (78\%) after 4 to 6 $\mathrm{h}$ of injection. The oral pretreatment of rats by extracts of

Table 2. Phenolic compounds in methanol and aqueous extracts of A. clavatus determined by HPLC-TOF/MS. RT, retention time; -, trace

\begin{tabular}{|c|c|c|c|}
\hline Coumpound & RT & ME mg phenolic $\mathrm{kg}^{-1}$ plant & AE mg phenolic $\mathrm{kg}^{-1}$ plant \\
\hline Gentisic acid & 4.39 & 24.60 & 23.69 \\
\hline Chlorogenic acid & 6.03 & 1839.77 & 180.17 \\
\hline 4-hydroxybenzoic acid & 6.59 & 41.75 & 17.65 \\
\hline Protocatechuic acid & 6.96 & 26.64 & 22.34 \\
\hline Caffeic acid & 7.68 & 21.41 & - \\
\hline Syringic acid & 8.04 & 28.06 & 24.45 \\
\hline Vanillic acid & 8.69 & 12.99 & 10.30 \\
\hline Rutin & 9.51 & 0.92 & - \\
\hline Quercetin-3- $\beta$-D-glucoside & 10.03 & 51.98 & - \\
\hline Naringin & 10.60 & 4.59 & 0.07 \\
\hline Sinapic acid & 10.61 & 18.46 & - \\
\hline Polydatine & 10.76 & 4,29 & - \\
\hline Diosmin & 11.04 & 128.99 & 43.05 \\
\hline Apigetrin & 11.31 & 505.74 & 26.50 \\
\hline Cinnamic acid & 15.40 & - & 12.21 \\
\hline Apigenin & 16.48 & 173.75 & - \\
\hline
\end{tabular}




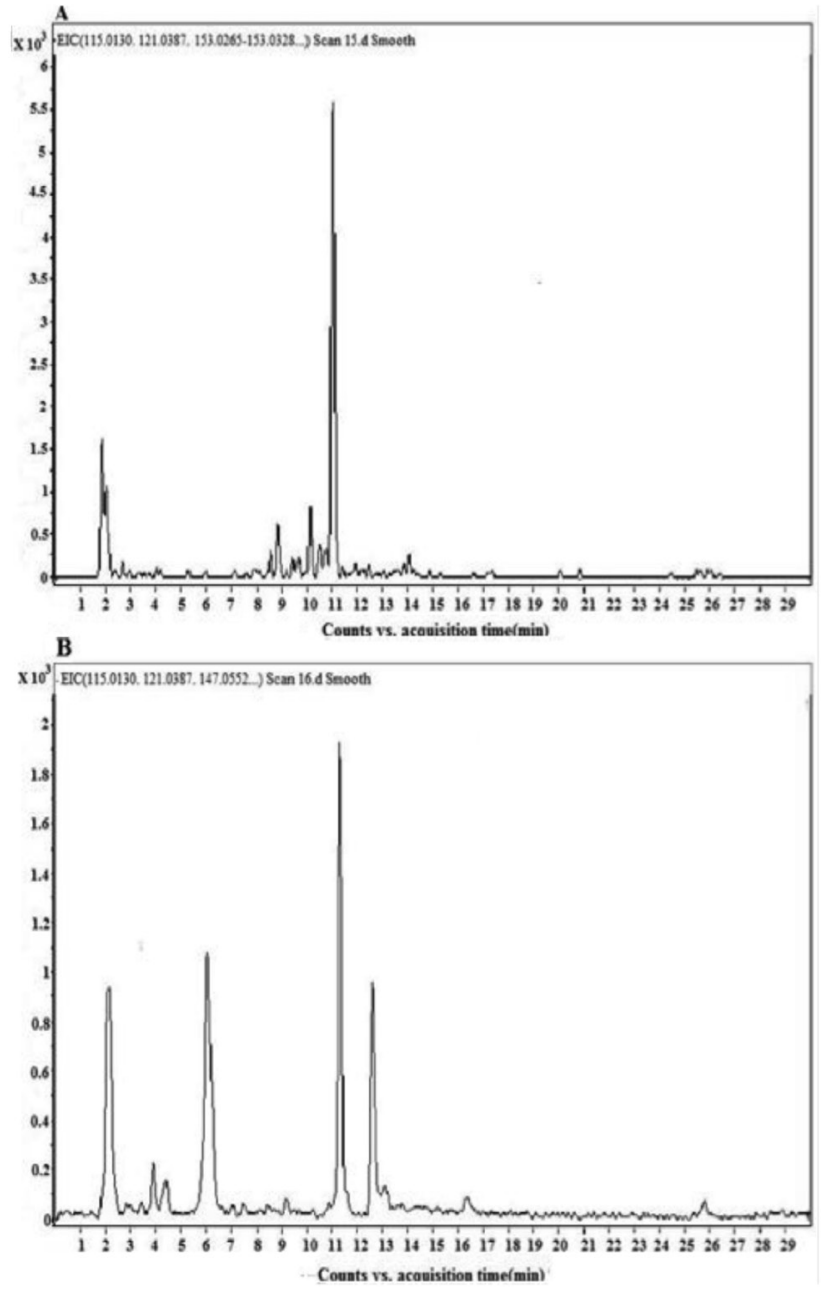

Fig. 1. HPLC chromatograms of phenolic compounds in $A$. clavatus methanol (A) and aqueous (B) extracts..

A. clavatus or aspirin significantly prevented the formation of edema. Indeed, the treatment of rats with $200 \mathrm{or} 400 \mathrm{mg}$ $\mathrm{kg}^{-1}$ of methanol extract inhibited the edema after $6 \mathrm{~h}$ by 64 and $74 \%$, respectively. At $400 \mathrm{mg} \mathrm{kg}^{-1}$ the inhibition was close to that of aspirin, which was used as a standard antiinflammatory agent. At the same doses, the aqueous extract exerted an anti-edematous effect with inhibition rates of 65 and $80 \%$, respectively (Fig. 3 ).

\section{Effect of Anacyclus clavatus extracts on carrageenan- induced pleurisy in rats}

The rats of the control group, which received orally saline solution, have developed after $4 \mathrm{~h}$ an acute pleurisy characterized by an exudate volume of $0.55 \pm 0.07 \mathrm{~mL}$ (Fig. 4A). This exudate contained $26.70 \pm 1.13 \times 10^{6} \mathrm{PMNs}$ (Fig. 4B). The pretreatment with $400 \mathrm{mg} \mathrm{kg}^{-1}$ of ME and $\mathrm{AE}$ decreased significantly the development of the pleurisy. Indeed, the methanol extract inhibited the exudation and the polymorphonuclear leukocyte migration by 64 and $66 \%$, respectively, compared with rats of the control group. At the same dose, aqueous extract inhibited the exudation

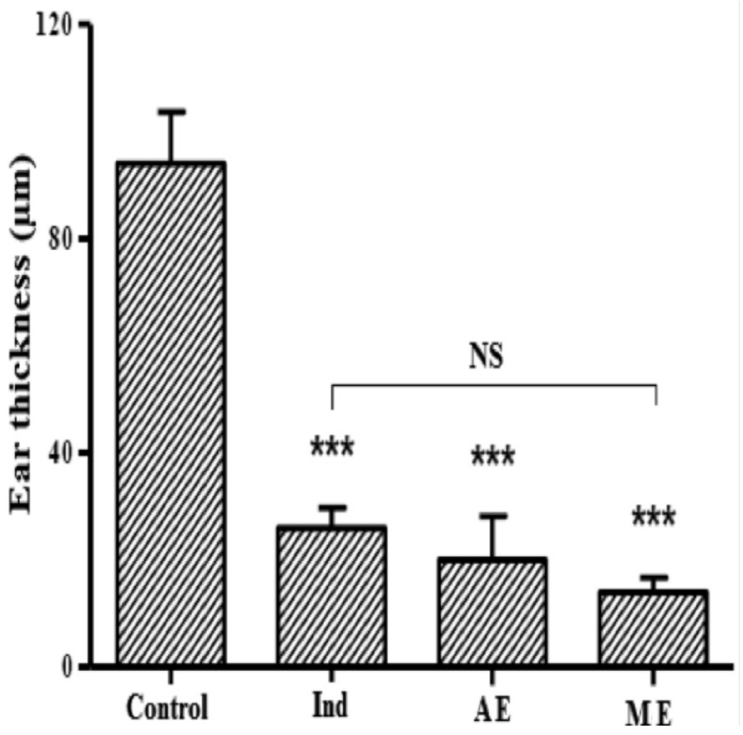

Fig. 2. Effect of A. clavatus extracts on croton oil-induced ear edema in mice. Mice were treated with $2 \mathrm{mg}$ per ear of methanolic extract (ME), aqueous extract (AE) or $0.5 \mathrm{mg}$ per ear of indomethacin (Ind). Control group received only sterile saline solution. Edema is expressed as mean thickness of ears before and $6 \mathrm{~h}$ after croton oil application. Values are expressed as means $\pm \mathrm{SE}$ $(n=6) .{ }^{* * *}, p<0.001$ vs control, NS, not significant.

by $42 \%$ and the number of migrating polymorphonuclear leukocytes into the exudates by $55 \%$. This inhibitory activity was less than that observed with aspirin at $200 \mathrm{mg} \mathrm{kg}^{-1}$,

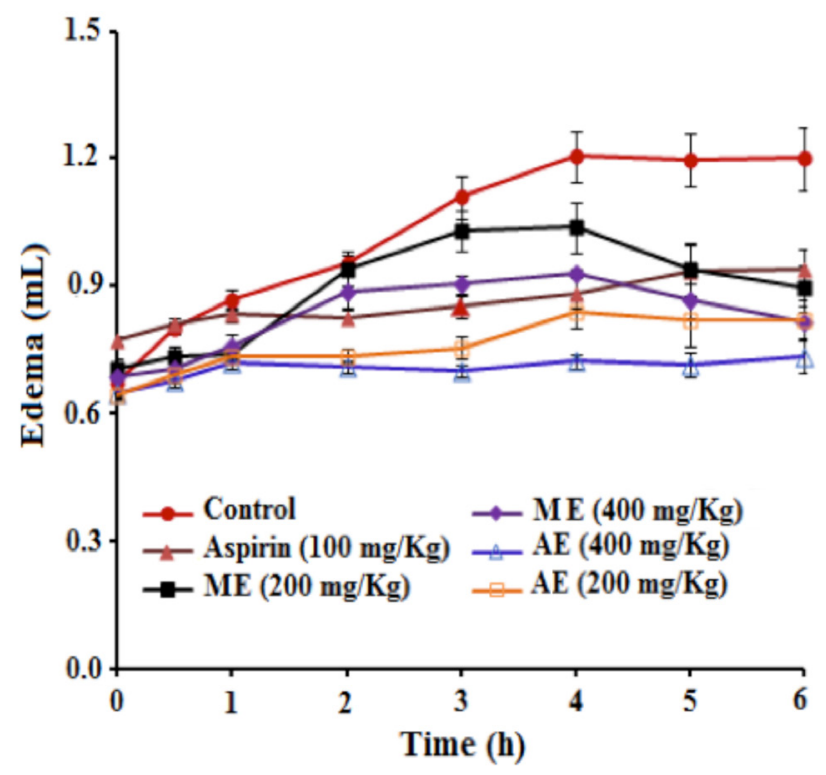

Fig. 3. Effect of A. clavatus extracts on carrageenan-induced paw edema in rat. The edema was induced by sub-plantar injection of $0.1 \mathrm{~mL}$ of carrageenan $1 \%$ in the rat pre-treated orally with $200 \mathrm{mg}$ $\mathrm{kg}^{-1}$ and $400 \mathrm{mg} \mathrm{kg}^{-1}$ of methanolic extract (ME), aqueous extract (AE) and $100 \mathrm{mg} \mathrm{kg}^{-1}$ body weight of aspirin. The control received only the saline solution. Each value represents the increase in volume of the injected paw at different times after injection of carrageenan. Values are means $\pm \operatorname{SE}(n=6)$. 

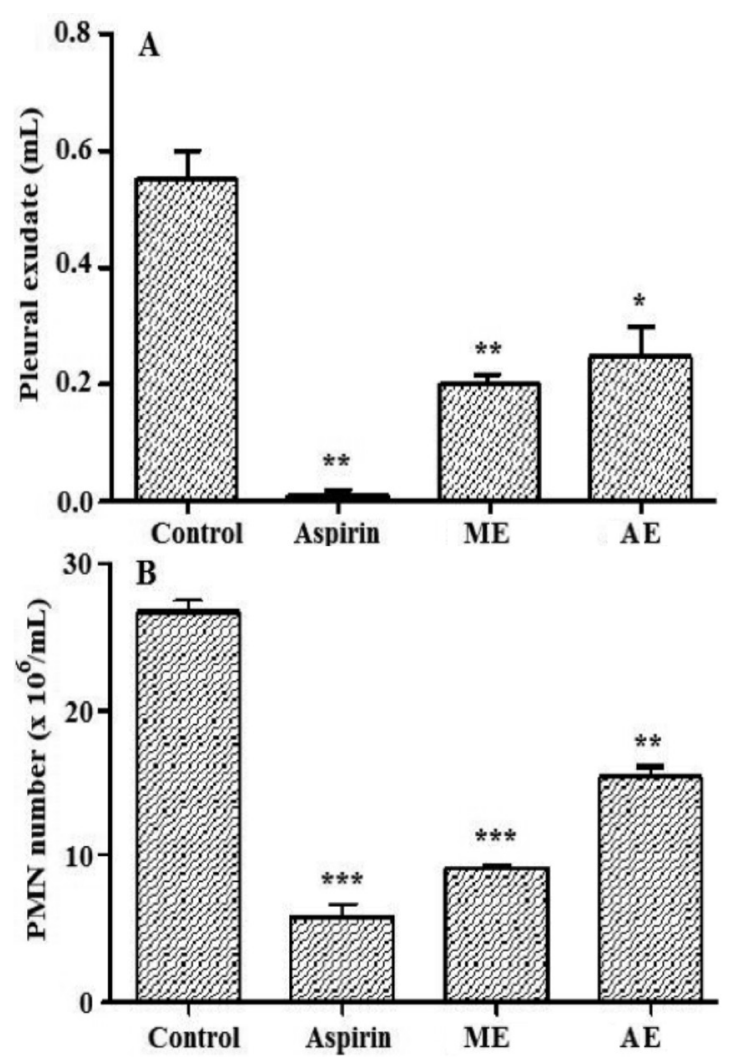

Fig. 4. Effect of $A$. clavatus extraxts on $\lambda$-carrageenan-induced pleurisy in rats. Rats were pretreated orally with $400 \mathrm{mg} \mathrm{kg}$ methanol (ME), aqueous (AE) extracts or $200 \mathrm{mg} \mathrm{kg}^{-1}$ aspirin. The control was pretreated with normal saline solution and then injected by $\lambda$-carrageenan. $A$, volume of exudate aspirated from the pleural cavity $4 \mathrm{~h}$ after the injection of $\lambda$-carrageenan. $\mathrm{B}$, number of polymorphonuclear leukocytes (PMNs) migrated into exudates $4 \mathrm{~h}$ after the injection of $\lambda$-carrageenan. Results are expressed as mean $\pm \operatorname{SE}(n=6) .{ }^{* *} p<0.001 ;{ }^{* *} p<0.01$ vs the control. .

which decreased the exudation by $98 \%$ and the number of polymorphonuclear leukocytes by $78 \%$ (Fig. 4 A,B).

\section{DPPH free radical scavenging activity}

A. clavatus aqueous and methanol extracts showed a concentration-dependent anti-radical activity (Fig 5). At $100 \mu \mathrm{g} \mathrm{mL} \mathrm{m}^{-1}$, methanol extract exerted maximum activity (90\%). This effect was better than that of the standard BHT, which in turn was better than that of aqueous extract. The $\mathrm{IC}_{50}$ of $\mathrm{ME}, \mathrm{AE}$ and $\mathrm{BHT}$ was $28.30 \pm 3.45,68.98 \pm 1.64$ and $44.36 \pm 3.10$, respectively.

\section{Metal chelating activity}

Results showed that both extracts of A. clavatus exerted chelating activity. However, the chelating activity of aqueous extract was better than that of the methanol extract. Indeed, at $300 \mu \mathrm{g} \mathrm{mL} \mathrm{m}^{-1}, \mathrm{AE}$ exerted $88 \%$ inhibition, whereas $\mathrm{ME}$ reached this percentage of inhibition only at $600 \mu \mathrm{g} \mathrm{mL}^{-1}$ (Fig. 6). EDTA used as a standard chelator exerted high chelation activity (99\%) at only $14 \mu \mathrm{g} \mathrm{mL} \mathrm{m}^{-1}$.

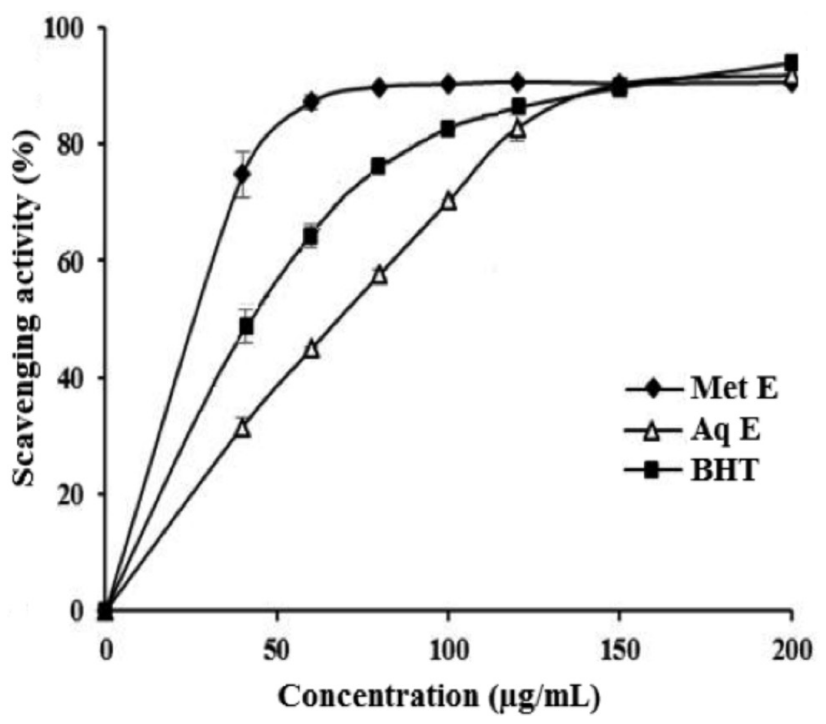

Fig. 5. Free radical scavenging activity of methanolic extract (ME), aqueous extract (AE) of $A$. clavatus and butylated hydroxytoluene (BHT). Values are means $\pm \operatorname{SD}(n=3)$..

The $\mathrm{IC}_{50}$ obtained with $\mathrm{AE}, \mathrm{ME}$ and EDTA was $74.64 \pm$ $11.68,152.93 \pm 1.67$, and $5.97 \pm 0.20$, respectively.

\section{Total antioxidant activity}

Fig. 7 shows the kinetics of linoleic acid peroxidation in the presence and absence of $\mathrm{ME}, \mathrm{AE}$ and $\mathrm{BHT}$. The absorbance of the samples was stable throughout the $96 \mathrm{~h}$ of incubation, indicating strong antioxidant activity compared to the control. At $50 \mu \mathrm{g} \mathrm{mL} \mathrm{m}^{-1}, \mathrm{ME}$ and AE inhibited lipid peroxidation by $75 \%$. This value is statistically similar to that of BHT. At the same concentration, BHT exerted inhibition of 77\% (Fig. 7).

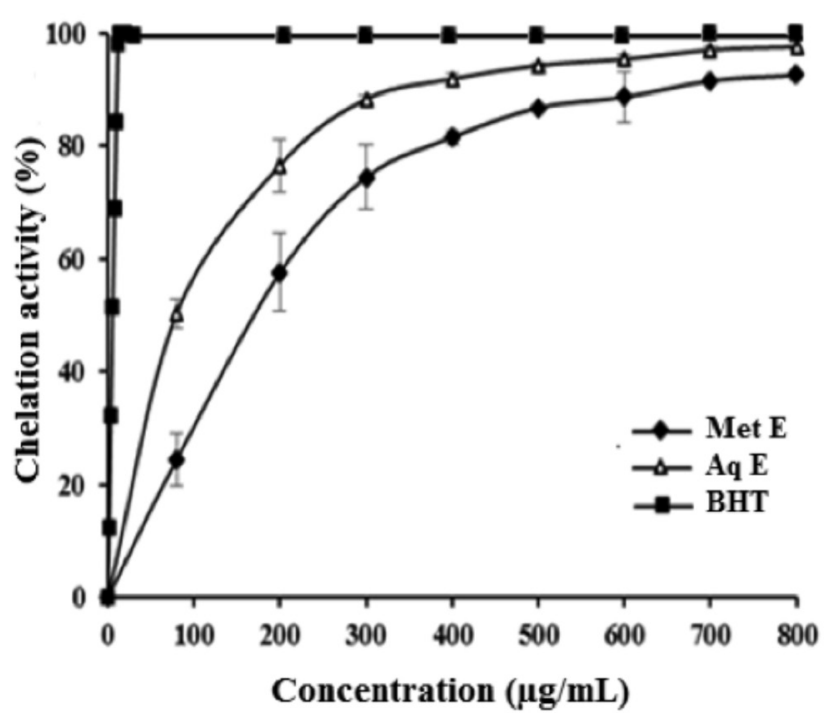

Fig. 6. Ferrous ion chelating activity of methanolic extract (ME), aqueous extract (AE) of A. clavatus and EDTA. Values are means $\pm \mathrm{SD}(n=3)$.. 


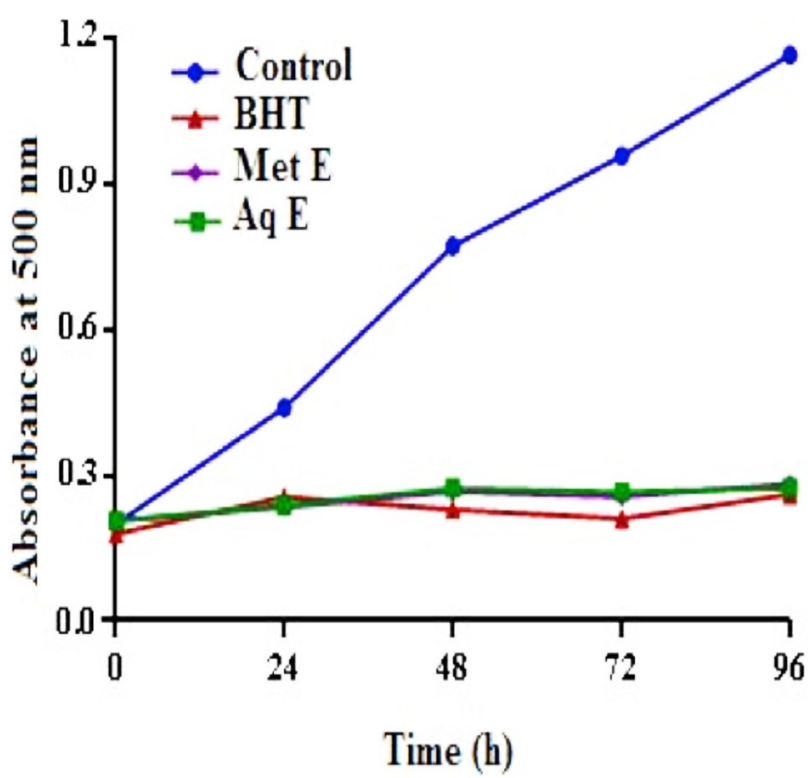

Fig. 7. Kinetics of the inhibition of lipid peroxidation by methanolic extract (ME), aqueous extract (AE) of A. clavatus and butylated hydroxytoluene (BHT). Values are means $\pm \operatorname{SD}(n=3)$.

\section{Discussion}

Anti-inflammatory drugs and synthetic antioxidants are often associated with several adverse effects on human health, such as gastrointestinal ulcers and cardiovascular risk (Al-Saeed 2011), and liver damage and carcinogenesis (Gulcin et al. 2005). Therefore, the development of alternative anti-inflammatory agents and antioxidants mainly from natural sources has attracted considerable attention. Medicinal plants may offer a safer and an effective alternative treatment for inflammatory and oxidative-stress related diseases. In this context, the anti-inflammatory and the antioxidant properties of Anacyclus clavatus were investigated.

To study the inflammatory processes, a croton oilinduced ear edema experimental model is wide used. In this model, edema events are triggered by protein kinase $\mathrm{C}$, which leads to phospholipase $\mathrm{A}_{2}$ activation and then the release of a variety of bioactive eicosanoids, which are implicated in the development of inflammatory events (Cuzzocrea 1998). Also, protein kinase C promotes various immune mediators such as cytokines and chemokines, which increase and maintain the inflammatory response (Kim et al.2013). Croton oil is able to activate protein kinase C, which in turn activates other enzymatic cascades, such as cyclooxygenase 2 and inducible nitric oxide synthase (Aquila et al. 2009). This cascade of events stimulates vascular permeability, vasodilation, polymorphonuclear leukocyte migration, histamine and serotonin release and activates synthesis of eicosanoids by cyclooxygenase and 5-lipoxygenase enzymes (Cuzzocrea 1998). Local pre-treatment of ear mice with A. clavatus methanol and aqueous extracts reduced significantly the size of the ear edema (Fig. 2). This effect was better than that exerted by indomethacin, used as standard anti-inflammatory drug to inhibit cyclooxygenase 1 and 2, the formation of exudate and the production of the pro-inflammatory mediators such as TNF $\alpha$, IL-6 and PGE2 (Bidaut-Russell 2008). The activity observed with the studied extracts is probably due to the presence of active substances that can cross the skin barrier and exert anti-inflammatory effect (Manga et al. 2004). Flavonoids and polyphenols are likely candidates for this effect (Gonzalez et al. 2011; Zhong et al., 2012).

In the carrageenan-induced paw edema model, the subcutaneous injection of carrageenan into the rat paw produced plasma exudation associated with the migration of neutrophils into the inflated site and increased arachidonic acid product release (Cuzocrea 1998). Oral administration of $A$. clavatus extracts elicited a significant reduction of paw edema formation at all assessment times (Fig. 3), which indicated that these extracts contain compounds that may act as anti-inflammatory agents by inhibiting the release the pro-inflammatory mediators. In fact, Romier-Crouzet et al. (2009) reported the inhibition of inflammatory mediators by polyphenolic plant extracts.

Moreover, oral administration of $A$. clavatus extracts significantly attenuated the development of pleurisy (Fig. $4 \mathrm{~A}, \mathrm{~B})$, by inhibiting plasma exudation as well as leukocyte recruitment to the inflated site after $4 \mathrm{~h}$ following the induction of pleurisy by $\lambda$-carrageenan. This result may attribute to the phyto-constituents of the extracts that are able to reduce the production of mediators involved in the development of the acute inflammatory reaction. Indeed, phytochemical screening showed that both studied extracts are rich in flavonoids, polyphenols and tannins. These compounds are good inhibitors of serotonin, histamine and leukocyte migration (Middleton et al. 2000). Flavonoids have been found to have anti-inflammatory activity in both proliferative and exudative inflammation phases, and they inhibit histamine, cytokine, prostaglandin and leukotriene release (Park et al. 2008; Rathee et al. 2009). Furthermore, phenolic compounds are a very effective treatment against inflammatory disorders (Gonzalez 2011).

The observed anti-inflammatory effects of $A$. clavatus extracts may be due also to the presence of antioxidant compounds. In fact, reactive oxygen species generated during inflammation by phagocytic cells and during the metabolism of arachidonic acid can activate the phospholipase $\mathrm{A}_{2}$, which releases more arachidonic acid from the phospholipid membrane, which is subsequently transformed into pro-inflammatory prostaglandins and leukotrienes (Geronikaki, Gavalas, 2006). This suggestion is supported by the obtained antioxidant results. Indeed, both extracts of extracts of $A$. clavatus exhibited a significant anti-radical, iron chelating, and anti-lipid peroxidation activity.

The DPPH radical scavenging activity of the two extracts 
was concentration-dependent (Fig. 5). Methanolic extract, which showed the highest content of phenolic compounds exhibited the highest scavenging activity (90\%). There is a close positive correlation between phenolic content and antioxidant activity (Zhao et al. 2014). The antioxidant activity of phenolic compounds is mainly due to their redox properties, which can play an important role in absorbing and neutralising free radicals by their hydrogen donating ability (Prasad et al. 2010).

The metal chelating activity is based on chelating of $\mathrm{Fe}^{2+}$ ions by the reagent ferrozine, which leads to the formation of ferrozine- $\mathrm{Fe}^{2+}$ ions complex (Dinis et al. 1994). A. clavatus aqueous extract exhibited a chelating activity higher than the methanol extract (Fig. 6). This result indicates that the aqueous constituents are more able to inhibit the formation of ferrous complex with the reagent ferrozine, suggesting the chelating activity of these extract and capture of the ferrous ions before ferrozine. It has been reported that chelating agents are effective as secondary antioxidants, as they reduce the redox potential, thereby stabilizing the oxidized form of the metal ions (Gulcin et al. 2007).

Lipid peroxidation is proceeded by radical-mediated abstraction of the hydrogen atom from a methylene carbon in a polyunsaturated fatty acid side chain (Yin et al. 2011), and the inhibitory effects on lipid peroxidation and autoxidation of linoleic acid have been attributed to the radical scavenging activity (Bajpa et al. 2014). Anacyclus clavatus extracts were similarly able to reduce linoleic acid peroxidation (Fig. 7). This ability to modify lipid peroxidation is linked not only to the structural characteristics of the antioxidants agents but also to their ability to interact with and penetrate the lipid bilayer (Salcedo et al. 2014). It has been shown that the structure and the lipophilicity of polyphenols are determinant factors of antioxidant properties of these compounds in the lipid layer of the membrane (Djeridane et al. 20010). Phenolic compounds are the main class of natural antioxidants and there is a close positive correlation between the phenolic content and antioxidant activity of plant extracts (Zhao et al. 2014).

In conclusion, Anacyclus clavatus extracts exhibit antiinflammatory and antioxidant activities, and phenolic constituents could be responsible for these activities. This plant may be considered as new promising source for functional foods and pharmaceuticals.

\section{Acknowledgements}

The authors are thankful to the Algerian Ministry of High Education for providing facilities to carry out the research work.

\section{References}

Abay G., Altun M., Koldaş S., Tüfekçi A.R., Demirtas I. 2015. Determination of antiproliferative activities of volatile contents and HPLC profiles of Dicranum scoparium
(Dicranaceae, Bryophyta). Comb. Chem. High Throughput Screen. 18: 453-463.

Al-Saeed A. 2011. Gastrointestinal and cardiovascular risk of nonsteroidal anti-inflammatory drugs. Oman. Med. J. 26: 385-391.

Aliboudhar H., Tigrine-Kordjani N. 2014. Effect of extraction technique on the content and antioxidant activity of crude extract of Anacyclus clavatus flowers and their essential oil composition. Nat. Prod. Res. 28: 2140-2149.

Aquila S., Giner R.M., Recio M.C., Spegazzini E.D., Rios J.L. 2009. Anti-inflammatory activity of flavonoids from Cayaponia tayuya roots. J. Ethnopharmacol. 121: 333-337.

Bahorun T., Gressier B., Trotin F., Brunet C., Dine T., Luyckx M., Vasseur J., Cazin M., Cazin J.C., Pinkas M. 1996. Oxygen species scavenging activity of phenolic extracts from hawthorn fresh plant organs and pharmaceutical preparations. Arzneimittelforschung 46: 1086-1089.

Bajpa V.K., Sharma A., Kang S.C., Baek K-H. 2014. Antioxidant, lipid peroxidation inhibition and free radical scavenging efficacy of a diterpenoid compound sugiol isolated from Metasequoia glyptostroboides. Asian Pac. J.Trop. Med. 7: 9-15.

Benitez G., Gonzalez-Tejero M.R., Molero-Mesa J. 2010. Pharmaceutical ethnobotany in the western part of Granada province (southern Spain): ethnopharmacological synthesis. J. Ethnopharmacol. 129: 87-105.

Bidaut-Russell M. 2001. Adverse gastrointestinal effects of NSAIDs: consequences and costs. Best Pract. Res. Clin. Gastroenterol. 15: 739-753.

Costa A., Garcia-Diaz D.F., Jimenez P., Silva P.I. 2013. Bioactive compounds and health benefits of exotic tropical red-black berries. J. Funct. Food. 5: 539-549.

Cuzzocrea S., Zingarelli B., Hake P., Salzman A.L. Szabo C. 1998. Anti-inflammatory effects of mercaptoethylguanidine, a combined inhibitor of nitric oxide synthase and peroxynitrite scavenger, in carrageenan-induced models of inflammation. Free Radic. Biol. Med. 24: 450-459.

Dinis T.C.P., Madeira V.M.C., Almeida L.M. 1994. Action of phenolic derivatives (acetaminophen, salicylate and 5-aminosalicylate) as inhibitors of membrane lipid peroxidation as peroxyl radical scavenging. Chem. Pharmacol. Bull. 315: 161-169.

Djeridane A., Yousfi M., Brunel J.M., Stocker P. 2010. Isolation and characterization of a new steroid derivative as a powerful antioxidant from Cleome arabica in screening the in vitro antioxidant capacity of 18 Algerian medicinal plants. Food Chem. Toxicol. 48: 2599-2606.

Geronikaki AA., Gavalas AM. 2006. Antioxidants and inflammatory disease: synthetic and natural antioxidants with anti-inflammatory activity. Comb. Chem. High Throughput Screen. 9: 425-442.

Gonzalez R., Ballester I., López-Posadas R., Suárez M.D., Zarzuelo A., Martínez-Augustin O., Sanchez de Medina F. 2011. Effects of flavonoids and other polyphenols on inflammation. Crit. Rev. Food Sci. Nutr. 51: 331-362.

Gulcin I., Alici H.A., Cesur M. 2005. Determination of in vitro antioxidant and radical scavenging activities of propofol. Chem. Pharm. Bull. 53: 281-285.

Gulcin I., Elmastat M., Aboul-Enein H.Y. 2007. Determination of antioxidant and antiradical scavenging activity of basil (Ocimum basilicum L. family Lamiaceae) assayed by different methodologies. Phytother. Res. 21: 354-361.

Hagerman A.E., Butler L.G. 1989. Choosing appropriate methods 
and standards for assaying tannin. J. Chem. Ecol. 15: 17951810.

Hammami S., Ben Salem A., Mastouri M., Falconieri D., Gorcii M., M'henni1 M.F., Marongiu B., Mighri Z. 2013. Essential oil composition and antimicrobial activities of aerial parts from Tunisian Anacyclus clavatus (Desf.). J. Med. Plant Res. 7: 71-75.

Kim H., Zamel R., Bai X-H., Liu M. 2013. PKC Activation induces inflammatory response and cell death in human bronchial epithelial cells. PLoS One 18: e64182.

Lahlou M. 2013. The success of natural products in drug discovery. Pharmacol. Pharm. 4: 17-31.

Li H.B., Cheng K.W., Wong C.C., Fan K.W., Chen F., Jiang Y. 2007. Evaluation of antioxidant capacity and total phenolic content of different fractions of selected microalgae. Food Chem. 102: 771-776.

Manga H.M., Brkic D., Marie D.E., Quetin-Leclercq J. 2004. In vivo anti-inflammatory activity of Alchornea cordifolia (Schumach. \& Thonn.) Mull. Arg. (Euphorbiaceae). J. Ethnopharmacol. 92: 209-914.

Middleton E.Jr., Kandaswami C., Theoradies T.C. 2000. The effects of plant flavonoids on mammalian cells: Implications for inflammation, heart disease, and cancer. Pharmacol. Rev. 52: 673-751.

Mittal M.,, Siddiqui M.R., Tran K., Reddy S.P., Malik A.B., 2014. Reactive oxygen species in inflammation and tissue injury. Antioxid. Redox Signal. 20: 1126-1167.

Moura FA., Queiroz de Andrade K., Farias dos Santos JC., Pimentel Araujo OR., Fonseca Goulart M.O. 2015. Antioxidant therapy for treatment of inflammatory bowel disease: Does it work?. Redox Biol. 6: 617-639.

Oyaizu M. 1986. Studies on product of browning reaction prepared from glucose amine. Jap. J. Nutr. 44: 307-315.

Park HH., Lee S., Son H.Y., Park S.B., Kim M.S., Choi E.J., Singh T.S., Ha J.H., Lee M.G., Kim J.E., Hyun M.C., Kwon T.K., Kim Y.H., Kim S.H. 2008. Flavonoids inhibit histamine release and expression of pro-inflammatory cytokines in mast cells. Arch. Pharm. Res. 31: 1303-1311.

Prasad K.N., Xie H., Hao J., Yang B., Qiu S., Wei X., Chen F.,
Jiang Y. 2010. Antioxidant and anticancer activities of 8-hydroxypsoralen isolated from wampee [Clausena lansium (Lour.) Skeels] peel. Food Chem. 118: 62-66.

Que F., Mao L., Pan X. 2006. Antioxidant activities of five Chinese rice wines and the involvement of phenolic compounds. Food Res Int. 39: 581-587.

Rahman T., Hosen I., Towhidul Islam M.M., Shekhar H.U. 2012. Oxidative stress and human health. Adv. Biosci. Biotechnol. 3: 997-1019.

Rathee P., Chaudhary H., Rathee S., Rathee D., Kumar V., Kohli K. 2009. Mechanism of action of flavonoids as anti-inflammatory agents. Inflamm. Allergy Drug Targets 8: 229-235.

Romier-Crouzet B., Van De Walle J., During A., Joly A., Rousseau C., Henry O., Larondelle Y., Schneider Y.J. 2009. Inhibition of inflammatory mediators by polyphenolic plant extracts in human intestinal Caco-2 cells. Food Chem. Toxicol. 47: 12211230 .

Salcedo C.L., Frías M.A., Cutro A.C., Nazareno M.A., Disalvo E.A. 2014. Antiradical activity of gallic acid included in lipid interphases. Biochim. Biophys. Acta. 1838: 2656-2661.

Winter CA., Risley E.A., Nuss G.W., 1962. Carrageenan induced edema in the hind paw of the rat as an assay for antiinflammatory drugs. Proc. Soc. Exp. Biol. Med. 11: 544-547.

Yin H., Xu L., Porter N.A. 2011. Free radical lipid peroxidation: mechanisms and analysis. Chem. Rev. 111: 5944-5972.

Yi-Qun Y., Xia D., Yi-Chang J., Chuan-Xin H., Yi-Zheng W., YingHui X. 2008. Antitumor effect of $\beta$-elemene in glioblastoma cells depends on p38 MAPK activation. Cancer Lett. 264: 127-134.

Zhao H-X., Zhang H-S., Yang S-F. 2014. Phenolic compounds and its antioxidant activities in ethanolic extracts from seven cultivars of Chinese jujube. Food Sci. Human Wellness 3: 183190.

Zhong Y., Chiou Y.S., Pan M.H., Shahidi F. 2012. Antiinflammatory activity of lipophilic epigallocatechin gallate (EGCG) derivatives in LPS-stimulated murine macrophages. Food Chem. 134: 742-748. 